\title{
Abordagens semiquantitativa e quantitativa na avaliação da textura do solo por espectroscopia de reflectância bidirecional no VIS-NIR-SWIR
}

\author{
Marston Héracles Domingues Franceschini(1), José Alexandre M. Demattê(1), Marcus Vinicius Sato(1), \\ Luiz Eduardo Vicente ${ }^{(2)}$ e Célia Regina Grego(2)
}

\begin{abstract}
(1)Universidade de São Paulo, Escola Superior de Agricultura Luiz de Queiroz, Departamento de Ciência do Solo, Avenida Pádua Dias, no 11, Caixa Postal 09, CEP 13416-000 Piracicaba, SP, Brasil. E-mail: marston.franceschini@usp.br; jamdemat@usp.br; marcus.sato@usp.br (2)Embrapa Monitoramento por Satélite, Avenida Soldado Passarinho, no 303, CEP 13070-115 Campinas, SP, Brasil. E-mail: luiz.vicente@embrapa.br, celia.grego@embrapa.br
\end{abstract}

Resumo - O objetivo deste trabalho foi avaliar o potencial da espectroscopia de reflectância no VIS-NIR-SWIR, para a caracterização granulométrica de amostras de solos de diferentes classes texturais, e obter modelos de predição dos teores de argila, silte e areia no solo. Utilizou-se um conjunto de amostras representativas de Latossolos e Argissolo de cinco locais do Estado do Mato Grosso do Sul. Os espectros do visível e do infravermelho próximo ao infravermelho de ondas curtas (de 350 a $2.500 \mathrm{~nm}$ ) das amostras foram obtidos e analisados. Empregaram-se a análise de componentes principais (ACP), agrupamento por "fuzzy c-means", regressão logística multinomial (RLM) e regressão por mínimos quadrados parciais. Espectros característicos para as diferentes classes texturais e a segregação de amostras de classes texturais e de locais de coleta com características distintas, por meio da ACP, "fuzzy c-means" e RLM, mostram o potencial semiquantitativo dos dados de reflectância no VIS-NIR-SWIR. Obteve-se quantificação satisfatória quanto à argila $\left(\mathrm{R}^{2}=0,92, \mathrm{RPD}=3,59\right)$, ao silte $\left(\mathrm{R}^{2}=0,80, \mathrm{RPD}=2,15\right)$ e à areia $\left(\mathrm{R}^{2}=0,87, \mathrm{RPD}=2,62\right)$. As técnicas de espectroscopia de reflectância podem auxiliar na determinação da textura $\mathrm{e}$ da variabilidade espacial do solo com metodologias semiquantitativas ou quantitativas.

Termos para indexação: granulometria do solo, espectroscopia de reflectância, estatística multivariada, pedometria, sensoriamento próximo.

\section{Semiquantitative and quantitative approaches for soil texture evaluation through VIS-NIR-SWIR bidirectional reflectance spectroscopy}

\begin{abstract}
The objective of this work was to evaluate the potential of VIS-NIR-SWIR reflectance spectroscopy for the characterization of soil particle-size distribution of samples from different textural classes, and to obtain models to predict clay, silt, and sand contents in the soil. A representative sample set of Oxisols and Ultisols from five locations in Mato Grosso do Sul state, Brazil, were used. Visible and near-infrared to short-wave infrared (from 350 to $2,500 \mathrm{~nm}$ ) spectra of the samples were obtained and analyzed. Principal component analysis (PCA), fuzzy c-means cluster analysis, multinomial logistic regression (MLR), and partial least squares regression were used. Characteristic spectra for the different soil texture classes and segregation of samples from texture classes and from sampling sites with distinct characteristics, through PCA, fuzzy c-means, and RLM, show the semiquantitative potential of the VIS-NIR-SWIR reflectance data. Satisfactory quantification was obtained for clay $\left(\mathrm{R}^{2}=0.92\right.$, $\mathrm{RPD}=3.59)$, silt $\left(\mathrm{R}^{2}=0.80, \mathrm{RPD}=2.15\right)$, and sand $\left(\mathrm{R}^{2}=0.87, \mathrm{RPD}=2.62\right)$. The reflectance spectroscopy techniques can help to assess soil texture and soil spacial variability with semiquantitative or quantitative methodologies.
\end{abstract}

Index terms: soil granulometric distribution, reflectance spectroscopy, multivariate statistics, pedometrics, proximal sensing.

\section{Introdução}

A textura do solo é uma variável ambiental de grande interesse, por estar relacionada ao potencial produtivo e a processos de degradação dos solos (White, 2005); sua caracterização é imprescindível no planejamento agrícola, pois, em conjunto com outros fatores, permite determinar o manejo adequado do solo.

A análise da distribuição granulométrica do solo possibilita a atribuição das amostras a determinadas classes texturais, que são definidas e adotadas de acordo com a finalidade do estudo, como o mapeamento e a 
classificação do solo ou a determinação do potencial produtivo (ambiente de produção) de uma cultura. No Brasil, para fins de classificação do solo, são empregadas as classes texturais descritas por Santos et al. (2013). Para o ambiente produtivo, diversos sistemas foram propostos, como o relacionado ao manejo da cana-de-açúcar descrito por Demattê \& Demattê (2009).

Em geral, a determinação de atributos do solo somente por meio de coleta de amostras e análise em laboratório apresenta custo elevado, demanda muito tempo da coleta até a obtenção dos resultados e requer reagentes químicos que podem gerar impactos ambientais (Nanni \& Demattê, 2006). Assim, novas metodologias menos onerosas, mais rápidas e que mitiguem impactos ambientais são necessárias para viabilizar a caracterização mais detalhada do solo, em escala espacial e temporal compatível com o manejo agrícola e o monitoramento ambiental (Bellinaso et al., 2010).

A técnica de espectroscopia de reflectância vem sendo proposta como alternativa para auxiliar os métodos convencionais na determinação de atributos do solo (Madari et al., 2006; Viscarra Rossel et al., 2009; Vendrame et al., 2012). Sousa Junior et al. (2011) observaram que a determinação da distribuição granulométrica de uma amostra de solo seco e peneirado, pelo método convencional proposto por Bouyoucos (1962), leva aproximadamente 48 horas, enquanto a mesma determinação feita a partir de informação espectral do solo pelo VIS-NIR-SWIR (do visível e infravermelho próximo ao infravermelho de ondas curtas, 400 a $2.500 \mathrm{~nm}$ ) leva apenas cerca de $10 \mathrm{~min}$. Estes mesmos autores verificaram que, no Brasil, os aparelhos necessários para a realização das análises pelo método convencional custam mais do que o dobro do preço dos equipamentos utilizados na análise por espectroscopia de reflectância pelo VIS-NIR-SWIR.

O uso da espectroscopia de reflectância na determinação de atributos do solo é possível porque o espectro é resultado direto dos constituintes orgânicos, minerais e dos atributos físicos, como textura e teor de umidade do solo (Stenberg et al., 2010).

Mais especificamente no caso da textura do solo, a influência no VIS-NIR-SWIR ocorre quanto à intensidade da reflectância ao longo de toda a assinatura espectral (albedo), uma vez que solos com maior teor de argila tendem a apresentar maior agregação das partículas que os compõem, o que por sua vez ocasiona menor reflecção da energia eletromagnética incidente (Baumgardner et al., 1985; Bellinaso et al., 2010). Além disto, os minerais da fração argila, como filossilicatos e óxidos, hidróxidos e oxi-hidróxidos de ferro e alumínio são os principais responsáveis por feições de absorção presentes no espectro de reflectância do solo pelo VIS-NIR-SWIR (Stenberg et al., 2010). Também a resposta espectral do quartzo no VIS-NIR-SWIR, mineral abundante na fração areia, é caracterizada por forte albedo e ausência de feições de absorção, o que é geralmente observado no espectro de solos arenosos (Bellinaso et al., 2010). A presença de minerais opacos como magnetita e ilmenita, em solos derivados de material de origem rico em ferro, afetam as leituras espectrais, por apresentar albedo muito baixo e ausência de feições de absorção nesta região do espectro eletromagnético (Vicente \& Souza Filho, 2011).

Demattê \& Garcia (1999) destacam o potencial da espectroscopia de reflectância do VIS-NIR-SWIR para o estudo do solo, inclusive quanto à predição da textura, em diferentes regiões do Brasil.

O objetivo deste trabalho foi avaliar o potencial da espectroscopia de reflectância do VIS-NIR-SWIR, para a caracterização granulométrica de solos com diferentes classes texturais, e obter modelos de predição dos teores de argila, silte e areia.

\section{Material e Métodos}

Foram coletadas 129 amostras de solo da camada 0-20 cm de profundidade, de cinco áreas situadas no Estado do Mato Grosso do Sul, vinculadas ao projeto AGSPEC (Agricultura e Espectroscopia de Reflectância), da Embrapa Monitoramento por Satélite (2013) (Tabela 1). Os locais de coleta apresentam relevo suave-ondulado e embasamento geológico composto principalmente de rochas ígneas do Cretáceo e de depósitos coluvionares do Quaternário (Geologia e recursos minerais do Estado do Mato Grosso do Sul, 2006).

As coletas foram realizadas em grade amostral, a fim de representar de forma adequada a variabilidade dos solos nas áreas estudadas. As amostras foram secas à $45^{\circ} \mathrm{C}$ por 48 horas, moídas e peneiradas em malha de $2 \mathrm{~mm}$. Em seguida, foram submetidas à análise granulométrica para a determinação das frações argila, silte e areia. Para isto, alíquotas de $40 \mathrm{~g}$ das amostras foram submetidas à dispersão em $250 \mathrm{~mL}$ de 
solução, com $4 \mathrm{~g} \mathrm{~L}^{-1}$ de hidróxido de sódio e $10 \mathrm{~g} \mathrm{~L}^{-1}$ de hexametafosfato de sódio, e agitadas por 16 horas a $120 \mathrm{rpm}$, em recipiente de $500 \mathrm{~mL}$. Após a dispersão mecânica, utilizou-se uma peneira com malha de $0,053 \mathrm{~cm}$ de abertura para separar a fração areia total. O material retido na peneira foi lavado e seco em estufa a $105^{\circ} \mathrm{C}$ por 24 horas para, posteriormente, ser pesado. O restante da suspensão, que continha as frações silte e argila, foi recolhido em proveta de $1 \mathrm{~L}$, e o volume foi completado com água destilada. A suspensão foi homogeneizada por $30 \mathrm{~s}$ e deixada em repouso por 24 horas para a sedimentação da fração silte. A fração argila foi estimada por meio de leitura de hidrômetro (densímetro) conforme Bouyoucos (1962). A fração silte foi obtida pela dedução das frações argila e areia do total para a amostra. O teor de matéria orgânica das amostras foi determinado de acordo com a metodologia descrita por Raij et al. (2001).

O espectro de reflectância das amostras foi obtido com o sensor FieldSpec 3 (Analytical Spectral Devices, Boulder, CO, EUA), e as leituras radiométricas foram registradas com resolução espectral final de $1 \mathrm{~nm}$, conforme Bellinaso et al. (2010). Para a realização das medições espectrais, as alíquotas de solo seco e peneirado foram colocadas e distribuídas de forma homogênea em placas de Petri, a fim de que a superfície das amostras estivesse relativamente plana para as leituras. O sensor utilizado captou a luz através de cabo de fibra óptica, alocado a $8 \mathrm{~cm}$ da superfície da amostra.
A área de leitura do sensor foi de aproximadamente $2 \mathrm{~cm}^{2}$, e a iluminação foi fornecida por duas lâmpadas halógenas externas de $50 \mathrm{~W}$, com feixe não colimado para o plano visado. As lâmpadas foram posicionadas a $35 \mathrm{~cm}$ de distância da amostra, com ângulo zenital de $30^{\circ}$, de modo a formar entre si um ângulo de $90^{\circ}$. Para a calibração do aparelho e obtenção das leituras de reflectância, utilizou-se uma placa de Spectralon como padrão de $100 \%$ de reflectância. Para cada amostra, foram obtidas três repetições, cada uma resultante de 100 leituras do sensor. A média destas três repetições foi adotada como comportamento espectral para a amostra.

Após a determinação da distribuição granulométrica do solo e da aquisição dos dados radiométricos, calculou-se o espectro médio para as diferentes classes texturais das amostras, classificadas conforme os teores de argila a seguir: arenosa (até 15\%), média (15 a $35 \%$ ), argilosa (35 a $60 \%$ ) e muito argilosa (acima de $60 \%$ ), quando consideradas as classes texturais para fins de classificação do solo conforme Santos et al. (2013); e arenosa (de 10 a 15\%), médio-arenosa (15 a $25 \%$ ), médio-argilosa (25 a 35\%), argilosa (35 a 65\%) e muito argilosa (maior que $65 \%$ ), classes texturais para fins de manejo do solo conforme Demattê \& Demattê (2009).

As curvas espectrais médias para cada classe textural foram, então, avaliadas pela comparação da forma, intensidade (albedo) e feições de absorção dos espectros médios conforme Demattê (2002).

Tabela 1. Descrição das áreas de estudos onde foram coletadas amostras de solo na camada 0-20 cm de profundidade, no Estado do Mato Grosso do Sul.

\begin{tabular}{|c|c|c|c|c|c|c|}
\hline Fazenda & $\begin{array}{l}\text { Muni- } \\
\text { cípio }\end{array}$ & $\begin{array}{c}\text { № de } \\
\text { amostras }\end{array}$ & Latitude $^{(1)}$ & Longitude $^{(1)}$ & Altitude $^{(2)}$ & Classes de solo predominante ${ }^{(3)}$ \\
\hline A & $\begin{array}{l}\text { Campo } \\
\text { Grande }\end{array}$ & 75 & $20^{\circ} 26^{\prime} 57,953 " \mathrm{~S}$ & $54^{\circ} 42^{\prime} 49,981^{\prime \prime O}$ & $540 \mathrm{~m}$ & $\begin{array}{l}\text { Latossolo Vermelho Distroférrico típico, textura muito argilosa e argilosa, A } \\
\text { moderado, fase cerradão tropical subcaducifólio e relevo plano. }\end{array}$ \\
\hline B & Jaraguari & 18 & $20^{\circ} 13^{\prime} 59,008^{\prime \prime S}$ & $54^{\circ} 29^{\prime} 33,013^{\prime \prime O}$ & $707 \mathrm{~m}$ & $\begin{array}{l}\text { Latossolo Vermelho Distrófico típico, textura média, A moderado, fase cerrado } \\
\text { tropical subcaducifólio, relevo suave ondulado. }\end{array}$ \\
\hline $\mathrm{C}$ & $\begin{array}{c}\text { Rio } \\
\text { Brilhante }\end{array}$ & 06 & $21^{\circ} 34^{\prime} 29,236^{\prime \prime S}$ & $54^{\circ} 47^{\prime} 24,498^{\prime \prime O}$ & $368 \mathrm{~m}$ & $\begin{array}{c}\text { Latossolo Vermelho Eutroférrico, pouco profundo, argiloso }+ \text { Latossolo } \\
\text { Vermelho Eutroférrico argiloso ou muito argiloso, relevo suave ondulado. }\end{array}$ \\
\hline $\mathrm{D}$ & Aquidauana & 12 & $19^{\circ} 37^{\prime} 29,025^{\prime \prime S}$ & $55^{\circ} 19^{\prime} 39,988^{\prime \prime O}$ & $164 \mathrm{~m}$ & $\begin{array}{l}\text { Argissolo Vermelho-Amarelo Distrófico típico, textura arenosa/média } \\
\text { e média/argilosa cascalhenta }+ \text { Argissolo Vermelho-Amarelo Distrófico } \\
\text { abrúptico, textura arenosa/média, ambos A moderado fase cerradão tropical } \\
\text { subcaducifólio, relevo suave ondulado. }\end{array}$ \\
\hline E & Maracaju & 18 & $21^{\circ} 45^{\prime} 0,158^{\prime \prime S}$ & $55^{\circ} 8^{\prime} 48,572^{\prime \prime O}$ & $416 \mathrm{~m}$ & $\begin{array}{c}\text { Latossolo Vermelho Distroférrico típico, álico + Latossolo Vermelho } \\
\text { Eutroférrico típico, ambos A moderado, textura muito argilosa e argilosa, fase } \\
\text { cerrado e cerradão tropical subcaducifólio, relevo plano + Latossolo Vermelho } \\
\text { Distroférrico cambissólico, A moderado, textura argilosa pouco cascalhenta, } \\
\text { fase cerrado tropical subcaducifólio, relevo suave ondulado. }\end{array}$ \\
\hline
\end{tabular}

${ }^{(1)}$ Datum WGS84. (2)Informações hipsométricas extraídas de Miranda (2005). ${ }^{(3)}$ Classes de solo predominantes nas fazendas A, B, D e E obtidas através de mapas de reconhecimento de baixa intensidade (escala 1:100.000) realizados por Motta et al. (2010), Oliveira et al. (2009), Silva et al. (2009) e Carvalho Junior et al. (2009), respectivamente, e para a fazenda C obtida através de mapa exploratório (escala $1: 1.000 .000)$ segundo Projeto Radambrasil (1982). 
A análise de componentes principais (ACP) foi realizada com os valores de reflectância, a fim de representar os dados altamente dimensionais dos espectros por meio de um espaço com poucas variáveis, que contivessem a maior parte da variabilidade dos dados originais (Varmuza \& Filzmoser, 2009). As coordenadas dos pontos amostrais no novo espaço gerado, chamadas de escores, foram formadas pelas combinações lineares das variáveis originais e pelos autovetores, os quais determinaram as dimensões do espaço gerado, ou as variáveis latentes obtidas.

O coeficiente de correlação de Pearson e a significância deste coeficiente entre os escores obtidos na ACP e os teores de argila, silte e areia do solo foram determinados, a fim de se avaliar a relação existente entre a variabilidade dos dados radiométricos, representada em cada componente, e a variação da textura do solo.

Os resultados da ACP foram empregados em uma análise de agrupamento com uso do algoritmo "fuzzy c-means" (Bezdek et al., 1984), por meio do qual foram atribuídos aos indivíduos (amostras) graus de associação a cada grupo obtido, que variam de 0 a 1 , o que permitiu a avaliação da relação de cada indivíduo com os diferentes grupos.

Como o algoritmo "fuzzy c-means" não indica diretamente o número ótimo de grupos para o conjunto de dados analisado, agrupamentos com 2 a 10 grupos foram obtidos, tendo-se empregado quatro parâmetros $\left(\mathrm{V}, \mathrm{V}_{\mathrm{XB}}, \mathrm{H}, \mathrm{F}\right)$ para a comparação da qualidade destes agrupamentos: a eficácia de agrupamento (V), de acordo com Varmuza \& Filzmoser (2009), em que a soma da distância (euclidiana) ao quadrado, entre os membros de cada grupo, foi dividida pela soma da distância (euclidiana) ao quadrado entre os grupos, e o menor valor foi indicativo da melhor distribuição dos grupos; o índice de validação $\left(\mathrm{V}_{\mathrm{XB}}\right)$, segundo Xie \& Beni (1991), e a entropia do agrupamento $(H)$, proposta por Bezdek et al. (1984), em que os menores valores foram correspondentes ao melhor agrupamento obtido; e o coeficiente de partição $(F)$, conforme descrito por Bezdek et al. (1984), para o qual o maior valor é sinal de grupos melhor distribuídos. O uso simultâneo destes diferentes parâmetros de avaliação $\left(\mathrm{V}, \mathrm{V}_{\mathrm{XB}}, \mathrm{H}, \mathrm{F}\right)$, para a escolha do número de grupos mais adequado, permitiu uma análise mais embasada da distribuição das amostras nos grupos.

Após a contabilização das observações de cada local de coleta (fazenda), nos grupos indicados pelo algoritmo "fuzzy c-means", foram obtidas tabelas de contingência e, por meio delas, calculados os $\mathrm{R}^{2}(\mathrm{U})$ associados, no programa JMP versão 9.0 (SAS Institute, Cary, NC, EUA). Este parâmetro avalia a associação entre variáveis categóricas, com interpretação semelhante à do coeficiente de determinação $\left(\mathrm{R}^{2}\right)$ para variáveis numéricas contínuas.

Empregou-se a regressão logística multinomial (RLM) para a avaliação específica do potencial de discriminação das amostras por meio do espectro, de acordo com as diferentes classes texturais propostas por Santos et al. (2013). Os modelos referentes à RLM foram ajustados conforme Hengl et al. (2007), tendose utilizado resultados da ACP como preditores. Isto permitiu a classificação das amostras nas diferentes classes texturais, a partir das variáveis latentes geradas pela ACP. Para obtenção e validação dos modelos de classificação, adaptou-se a metodologia descrita por Vasques et al. (2008). Assim, o conjunto de dados foi dividido de forma aleatória, no programa $\mathrm{R}(\mathrm{R}$ Development Core Team, 2012), em duas partes: conjunto de calibração (dois terços, 86 amostras) e de validação (um terço, 43 amostras). Realizou-se, ainda, o teste de igualdade de variância de Levene (Levene, 1960) e de médias (teste $t$ ) entre os conjuntos de calibração e validação, a fim de assegurar uma validação representativa dos modelos obtidos.

Para a avaliação dos modelos, gerou-se uma matriz de confusão com o resultado das predições feitas para o conjunto de validação, com a contabilização das observações e das predições de cada classe textural. Por meio da matriz de confusão, calculou-se o índice kappa $(\mathrm{k})$ e as acurácias do método $\left(\mathrm{A}_{\mathrm{M}}\right)$, para o usuário $\left(A_{U}\right)$ e global $\left(A_{G}\right)$, a fim de avaliar a acurácia da classificação obtida e do método empregado (Congalton \& Green, 2009). Para julgar o valor $\mathrm{k}$ calculado, foram considerados os intervalos amplamente adotados para este fim (Richards, 2013), com os seguintes valores: abaixo de 0,4 como indicação de uma classificação ruim; entre 0,41 e 0,6, moderada; entre 0,61 e 0,75, boa; entre 0,76 e 0,80 , excelente; e, para valores maiores que 0,81 , classificação quase perfeita.

Para a implementação do algoritmo "fuzzy c-means" e cálculo dos parâmetros $\mathrm{V}, \mathrm{V}_{\mathrm{XB}}, \mathrm{F}$ e $\mathrm{H}$, utilizou-se o pacote fclust (Giordani \& Ferraro, 2013). Os modelos de RLM foram obtidos com uso do pacote nnet (Venables \& Ripley, 2002), e o cálculo do índice k, por meio do pacote ved (Meyer et al., 2013). Todas as análises foram realizadas em ambiente computacional R (R Development Core Team, 2012). 
Para a obtenção de modelos de quantificação dos teores de argila, silte e areia do solo por meio da reflectância, utilizou-se a regressão por mínimos quadrados parciais ("partial least squares regression", PLSR), com validação cruzada para determinar o número ideal de fatores a serem adotados nos modelos (Viscarra Rossel et al., 2009).

Os cálculos tanto da ACP quanto da PLSR foram realizados por meio do programa ParLeS (Viscarra Rossel, 2008). Antes da obtenção dos modelos de quantificação, aplicaram-se tratamentos nos dados espectrais com o intuito de diminuir ruídos e não linearidades existentes. Foram testadas diferentes transformações - de reflectância, para logaritmo do inverso da reflectância (absorbância), SNV ("standard normal variate") e MSC ("multiple scattering correction") - amplamente empregadas no tratamento de dados espectrais, conforme proposto por Viscarra Rossel (2008). Testou-se também a remoção de ruídos, por meio dos filtros Savitzky-Golay (tendo-se adotado a polinomial de grau 2 e intervalos de três valores), Wavelet (nível 2) ou mediano (tendo-se adotado 2 como o tamanho da sequência a ser filtrada), assim como a centralização dos valores de acordo com a média, antes da aplicação das transformações.

Os mesmos conjuntos de calibração (86 amostras) e validação (43 amostras), empregados na RLM, foram utilizados na obtenção e validação dos modelos de quantificação por PLSR. Para a escolha dos modelos a serem utilizados, adotaram-se os seguintes critérios, para avaliar os resultados da validação cruzada, realizada com o conjunto de calibração (Viscarra Rossel et al., 2009): o coeficiente de determinação $\left(\mathrm{R}^{2}\right)$, a raiz quadrada do erro médio ao quadrado (RMSE), o parâmetro AIC ("Akaike's information criterion"), e o desvio percentual relativo (RPD).

Os modelos obtidos empregando o conjunto de calibração, correspondendo ao melhor número de fatores e tratamentos dos espectros para a predição dos teores de argila, silte e areia, foram aplicados na predição destes atributos para as amostras do conjunto de validação, e os valores de $\mathrm{R}^{2}$, RMSE e RPD referentes a estas predições foram avaliados.

\section{Resultados e Discussão}

No conjunto de dados, observaram-se amostras pertencentes a todas as classes texturais, para ambos os padrões considerados no estudo, com exceção da classe siltosa para a classificação do solo (Santos et al., 2013) e das classes muito arenosa e siltosa, na classificação para fins de manejo (Demattê \& Demattê, 2009). A textura argilosa foi a mais frequente, com a ocorrência de 55 e 86 amostras na classificação do solo e de manejo, respectivamente. Além disso, a maior parte das amostras estudadas pertence às classes argilosa ou muito argilosa (47 amostras ou 16 amostras nestes sistemas de classificação, respectivamente) e apresentaram entre 352 e $681 \mathrm{~g} \mathrm{~kg}^{-1}$ de argila.

As diversas classes texturais para fins de manejo e classificação do solo apresentaram curvas espectrais médias distintas (Figura 1), o que indicou que a análise morfológica e a comparação das curvas espectrais permitem separar amostras de solo diferentes quanto à textura, como observado também por Demattê (2002) e Bellinaso et al. (2010).

A intensidade de reflectância diminuiu das amostras arenosas para as muito argilosas, em todo espectro no VIS-NIR-SWIR, quando se considerou o espectro médio de cada classe textural, em ambos os sistemas de classificação da textura. Isto ocorreu principalmente pela maior agregação dos solos mais argilosos, o que, provavelmente, causou maior absorção da energia eletromagnética incidente e, também, pela influência do comportamento espectral do quartzo, com forte albedo e ausência de feições de absorção no VIS-NIR-SWIR, e pelo aumento da absorção ocasionada por minerais opacos, principalmente em solos argilosos e muito argilosos, ao longo de toda a assinatura espectral (Bellinaso et al., 2010; Vicente \& Souza Filho, 2011). Assim como observado por Demattê (2002), verificouse alteração dos ângulos das curvas espectrais, pois, os solos com maior teor de argila tenderam a ter aspecto plano e, à medida que aumentou o teor de areia, aumentou também a intensidade do infravermelho com ápice de reflectância a partir de $2.000 \mathrm{~nm}$.

A principal diferença que pode ser destacada entre os espectros médios, obtidos para as classes dos dois sistemas de classificação textural, foi o distanciamento ligeiramente maior do espectro médio das classes argilosa e muito argilosa, quando empregado o sistema proposto por Santos et al. (2013). Isto, provavelmente, ocorreu pelo fato de que a classe argilosa passou a ser mais restrita, com 350 a $600 \mathrm{~g} \mathrm{~kg}^{-1}$ de argila, ao invés de 350 a $650 \mathrm{~g} \mathrm{~kg}^{-1}$, o que a diferenciou mais da classe muito argilosa, na qual o teor máximo de argila observado para uma amostra foi de $681,0 \mathrm{~g} \mathrm{~kg}^{-1}$

Pesq. agropec. bras., Brasília, v.48, n.12, p.1569-1582, dez. 2013 DOI: $10.1590 / \mathrm{S} 0100-204 X 2013001200006$ 
no conjunto de dados estudados. Ainda, as diferenças observadas entre as curvas espectrais médias das classes texturais médio-arenosa e médio-argilosa, propostas por Demattê \& Demattê (2009) em substituição à classe textural média do sistema de Santos et al. (2013), indicam que a distinção entre amostras destas classes é possível por meio do espectro, mesmo sendo pequenos os intervalos correspondentes a cada uma delas (100 $\mathrm{g} \mathrm{kg}^{-1}$ de argila).

Além das variações do albedo entre amostras pertencentes a diferentes classes texturais, percebe-se
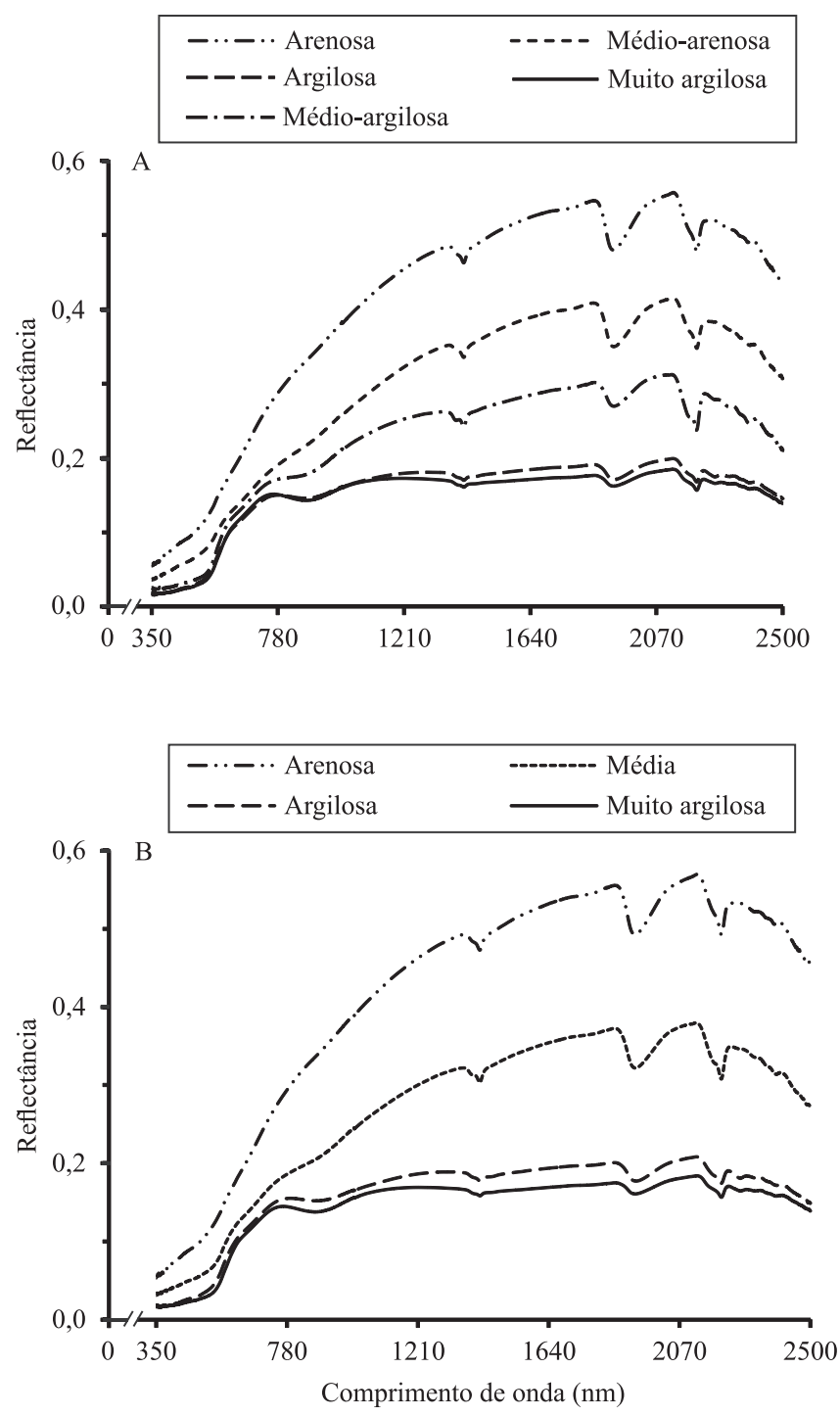

Figura 1. Curva espectral média das amostras de solo por classe textural, para fins de: A, manejo (Demattê \& Demattê, 2009); e B, classificação do solo (Santos et al., 2013). a intensificação das feições de absorção, à medida que cresce o teor de argila nas classes adotadas, em ambos os padrões de classificação da textura considerados, para as feições relativas aos óxidos, hidróxidos e oxi-hidróxidos de ferro, próximas a 530 e $880 \mathrm{~nm}$ (Viscarra Rossel et al., 2009; Stenberg et al., 2010). $\mathrm{O}$ aumento das feições de absorção associadas aos teores de óxidos, hidróxidos e oxi-hidróxidos de ferro pode ser resultado da influência do material de origem rico em ferro (Geologia e recursos minerais do Estado do Mato Grosso do Sul, 2006). Destaca-se que os solos com maior teor de argila apresentaram caráter férrico (Tabela 1), o que justifica nestes o aumento das feições de absorção associadas aos teores de óxidos, hidróxidos e oxi-hidróxidos de ferro.

Outro aspecto importante a ser considerado, quando se emprega informação espectral no estudo do solo, é o conteúdo de matéria orgânica (MO) das amostras. No conjunto de dados estudados, o teor de MO foi em média de $36 \mathrm{~g} \mathrm{~kg}^{-1}$, com coeficiente de variação $(\mathrm{CV})$ de $15 \%$, enquanto o CV observado para os teores de argila foi de $36,5 \%$. Embora a variação dos teores de $\mathrm{MO}$ tenha sido menor do que a observada para a textura, o conteúdo de MO pode ter afetado de forma significativa o espectro, considerando-se que os teores nas amostras foram superiores a $20 \mathrm{~g} \mathrm{~kg}^{-1}$, valor a partir do qual as propriedades espectrais da MO passam a influenciar de forma mais pronunciada a reflectância do solo (Baumgardner et al., 1985; Stenberg et al., 2010).

A ACP dos dados radiométricos permitiu diferenciar as amostras quanto à distribuição granulométrica (Figura 2). Na CP1, as amostras de textura média e arenosa encontram-se separadas das amostras argilosas e muito argilosas, o que indica que boa parte da informação espectral está associada à textura do solo. O resultado da análise de correlação entre os escores da ACP e os teores de argila, silte e areia mostrou que a $\mathrm{CP} 1$, que representou $75,8 \%$ da variabilidade espectral, resumiu parte dos dados radiométricos fortemente relacionada aos teores de argila e areia (Tabela 2). A CP3 representou informações espectrais melhor relacionadas à textura do solo, em comparação à $\mathrm{CP} 2$, embora a $\mathrm{CP} 3$ tenha correspondido à pequena parte da variabilidade contida nos dados radiométricos $(3,04 \%)$. Por sua vez, a confusão entre classes texturais foi bem maior na CP3 do que a observada na CP1 (Figura 2). 
A análise dos autovetores permitiu localizar as regiões do espectro que contribuíram de forma mais acentuada para a obtenção de cada componente, o que permitiu a avaliação da relação entre as informações espectrais representadas em cada $\mathrm{CP}$ e a textura do solo. No autovetor referente à $\mathrm{CP} 1$, componente que apresentou a maior correlação com os teores de argila e areia, observou-se a influência de comprimentos de onda a partir de $1.200 \mathrm{~nm}$, relacionados ao albedo, em contraste com comprimentos de onda próximos a 780 $\mathrm{nm}$, referentes principalmente a óxidos, hidróxidos e oxi-hidróxidos de ferro (Viscarra Rossel et al.,
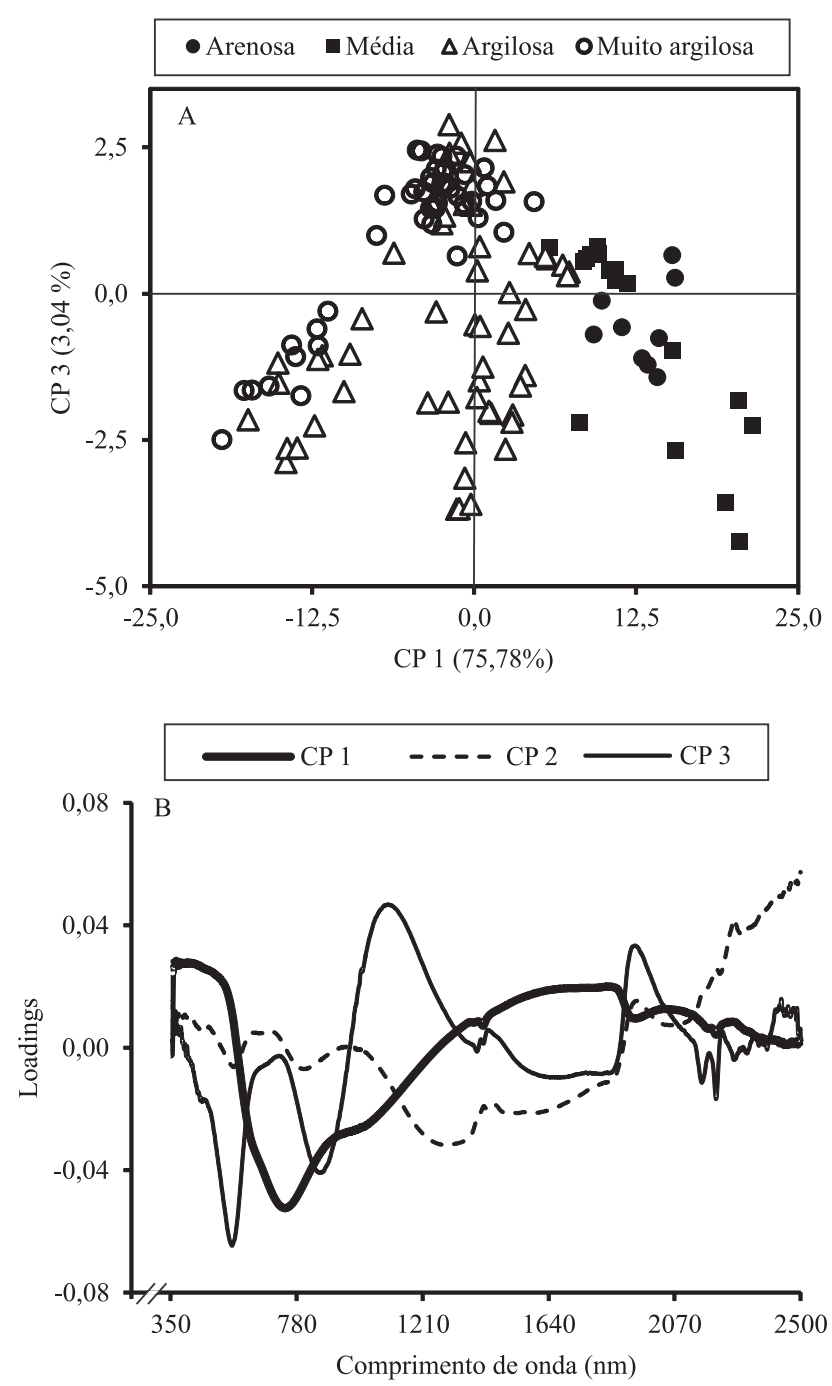

Figura 2. Gráficos dos escores da componente principal (CP) 1 e 3 (A), que exibem a classificação textural das amostras (Santos et al., 2013), e autovetores referentes às três primeiras $\mathrm{CP}(\mathrm{B})$.
2009). No autovetor da CP3, componente para a qual se obteve a segunda maior correlação com os teores argila e areia e a maior correlação com os teores de silte, também houve influência de feições de absorção associadas a minerais que contêm ferro, em 530 e $880 \mathrm{~nm}$, e igualmente de feições próximas a $2.200 \mathrm{~nm}$, relacionadas principalmente a filossilicatos e gibbsita, em contraste com a absorção de 1.000 a $1.200 \mathrm{~nm}$, referente ao albedo, e com a próxima a $1.900 \mathrm{~nm}$, ocasionada pela presença de água ou filossilicatos 2:1 com água em sua estrutura (Demattê et al. 2006; Stenberg et al. 2010). Assim, percebe-se a importância do albedo e de feições de absorção na região do visível, do infravermelho próximo e infravermelho de ondas curtas, referentes aos óxidos, hidróxidos e oxi-hidróxidos de ferro e alumínio e filossilicatos, na distinção das amostras quanto à textura, por meio dos dados espectrais.

O potencial de caracterização do solo por meio dos dados radiométricos foi evidenciado pelas análises de agrupamento (Figuras 3 e 4). O índice V, que leva em consideração as distâncias entre as amostras de cada grupo e a distância entre grupos, não indicou claramente qual o melhor agrupamento (Figura 3). De acordo com este índice, três, quatro ou cinco grupos poderiam ser empregados, se considerados os critérios propostos por Varmuza \& Filzmoser (2009). Assim, analisaram-se, de forma mais detalhada, os agrupamentos que continham quatro e cinco grupos, além do agrupamento com três grupos (indicado pela maioria dos índices; Figura 3).

No agrupamento com três grupos (Figura 4), verificou-se a separação do grupo I (9 amostras arenosas, 18 de textura média, 5 argilosas e 1 muito argilosa), composto predominantemente por amostras de textura arenosa e média, dos grupos II e III, que continham somente amostras argilosas e muito argilosas. Entre as cinco amostras argilosas incluídas no grupo I, quatro apresentaram entre 352,0 e $379,0 \mathrm{~g} \mathrm{~kg}^{-1}$ de argila, valores muito próximos dos

Tabela 2. Coeficientes de correlação de Pearson entre atributos e escores obtidos pela análise de componentes principais.

\begin{tabular}{lccc}
\hline Atributo & $\mathrm{CP} 1$ & $\mathrm{CP} 2$ & $\mathrm{CP} 3$ \\
\hline Argila & $-0,771^{* *}$ & 0,131 & $0,455^{* *}$ \\
Areia & $0,784^{* *}$ & $-0,025$ & $-0,300^{* *}$ \\
Silte & $-0,203^{*}$ & $-0,297^{*}$ & $-0,376^{*}$ \\
\hline
\end{tabular}

* e**Significativo a 5 e $1 \%$ de probabilidade, respectivamente. 
apresentados pela classe textural média. No grupo II, estavam incluídas 12 amostras argilosas e 10 muito argilosas e, no grupo III, 38 amostras argilosas e 36 muito argilosas. Na curva espectral média das amostras do grupo I, verificou-se um albedo alto, característica de solos mais arenosos (Bellinaso et al., 2010), assim como feições pouco acentuadas de absorção ocasionadas por óxidos, hidróxidos e oxi-hidróxidos de ferro e alumínio (Viscarra Rossel et al., 2009). Quanto às amostras dos grupos II e III, embora ambos conservassem a proporção de aproximadamente metade de amostras argilosas e metade de muito argilosas, o grupo II apresentou curva espectral média com menor intensidade (albedo).
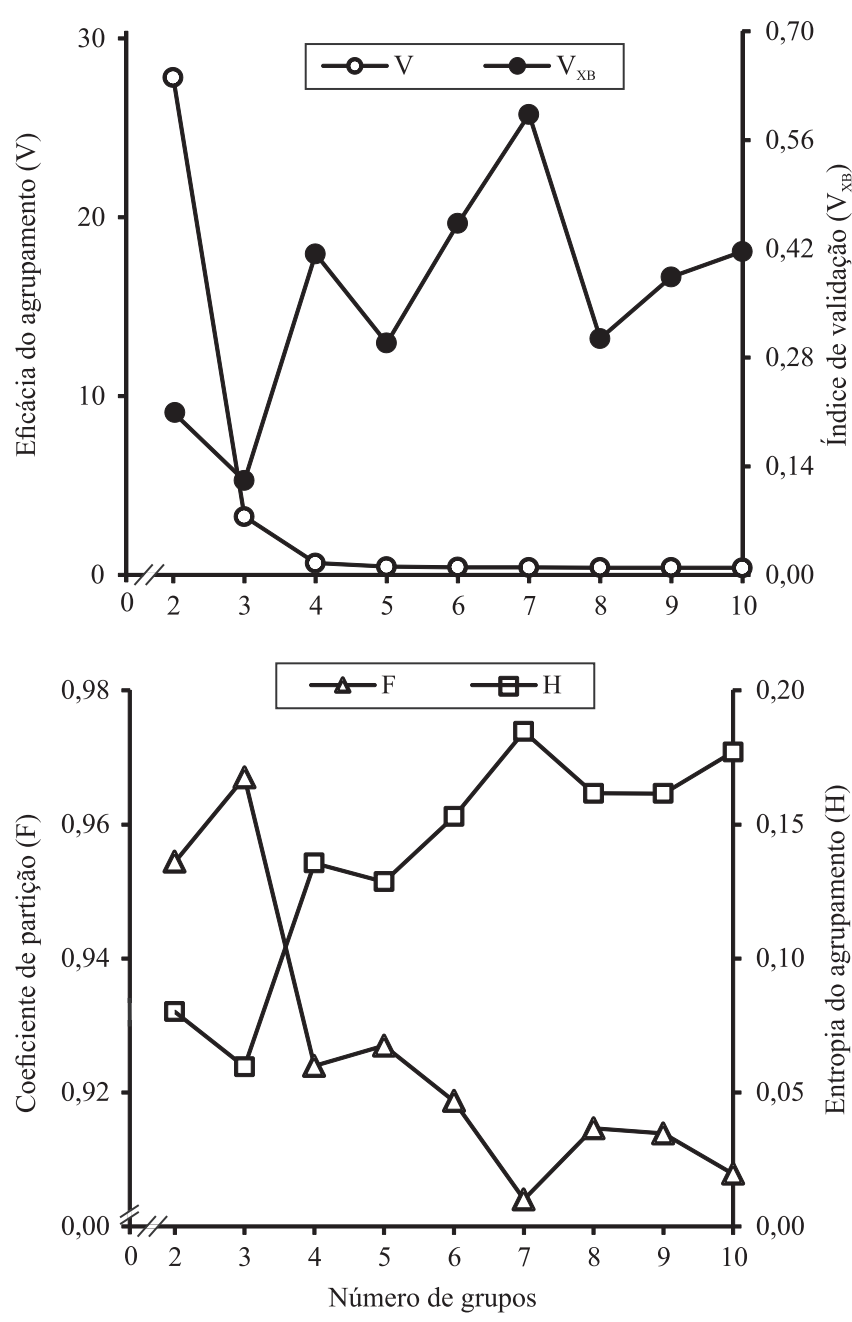

Figura 3. Parâmetros de avaliação dos agrupamentos obtidos pelo algoritmo "fuzzy c-means".
No agrupamento com quatro grupos, também ocorreu a separação das amostras argilosas e muito argilosas (grupos I, II e IV) de um grupo que continha amostras, em sua maioria, de textura arenosa ou média. As cinco amostras argilosas incluídas no grupo III apresentaram entre 352,0 e $379,0 \mathrm{~g} \mathrm{~kg}^{-1}$ de argila, com valores de distribuição granulométrica próximos dos da classe textural média. Assim como no agrupamento com três grupos, 12 amostras argilosas e 10 muito argilosas, com os maiores teores de óxidos, hidróxidos e oxi-hidróxidos de ferro e minerais opacos, foram reunidas no grupo II. As amostras argilosas e muito argilosas restantes foram atribuídas aos grupos I (45 amostras) e IV (30 amostras). No grupo I, a curva espectral média apresentou menor albedo e feições de absorção mais intensas em 530 e $880 \mathrm{~nm}$, o que indicou correspondência com solos com maior teor de argila e maiores teores de óxidos, hidróxidos e oxi-hidróxidos de ferro, em comparação com as amostras do grupo $\mathrm{IV}$, das quais 20 amostras eram argilosas e 10 muito argilosas.

Comparando-se a divisão das amostras em cinco grupos com a divisão feita em quatro grupos, a maior diferença foi observada com relação à separação das amostras de textura arenosa e média em dois grupos (I e III) (Figura 4). O grupo I, com seis amostras arenosas e seis de textura média, apresentou curva espectral média com maior albedo e menores feições de absorção referentes aos óxidos, hidróxidos e oxi-hidróxidos de ferro, em comparação aos demais grupos. No grupo III, predominaram amostras de textura média (12 amostras), mas foram incluídas também três amostras arenosas, seis argilosas (com cinco amostras que continham entre 352,0 e $379,0 \mathrm{~g} \mathrm{~kg}^{-1}$ de argila, valores muito próximos aos da textura média) e duas muito argilosas. O espectro médio para o grupo III apresentou menor albedo e feições de absorção relativas a óxidos, hidróxidos e oxi-hidróxidos de ferro mais acentuadas, do que a curva média para a classe I. Os demais grupos (II, IV e V) correspondem aos observados no agrupamento que contém quatro grupos (I, II e IV, respectivamente); é necessário subtrair apenas uma amostra do grupo I e duas amostras do grupo IV, do agrupamento que contém quatro grupos, para igualá-los aos grupos II e V, do agrupamento com cinco grupos.

A classificação textural das amostras (Figura 2), de acordo com Santos et al. (2013), e o espectro médio de 

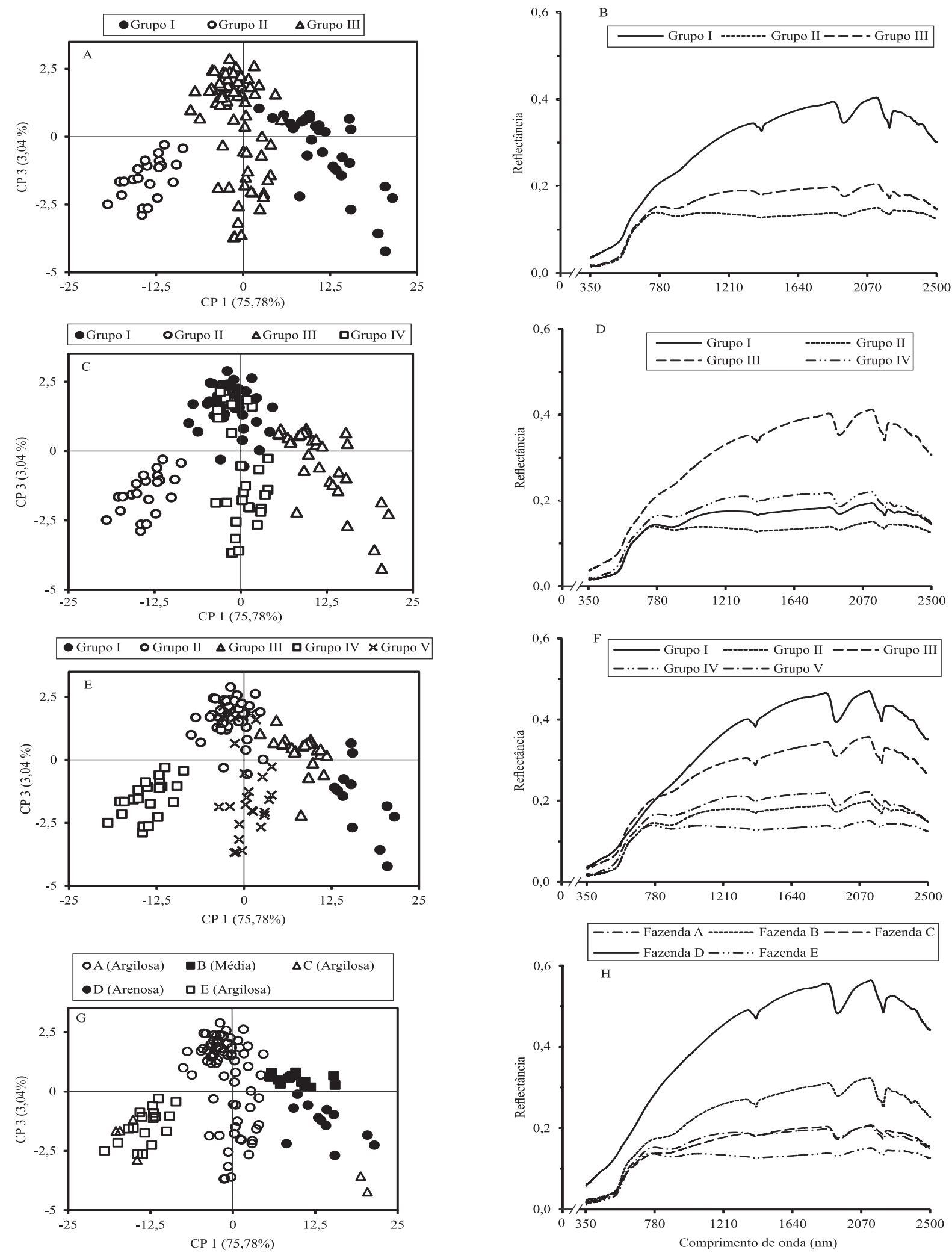

Figura 4. Gráficos dos escores da componente principal (CP) 1 e 3, em que se destaca o resultado da análise de agrupamento (A, C, E) e as amostras das fazendas A, B, C, D e E (G), bem como seus espectros médios (B, D, F, H). 
cada classe textural (Figura 1), assim como a separação das amostras por local de coleta (fazendas) e o espectro médio por fazenda (Figura 4), comparados à distribuição das amostras em grupos e ao comportamento espectral médio por grupo, permitem concluir que a separação dos grupos ocorreu por conta não só da variação da textura do solo, mas também pela variação de outras características diretamente relacionadas ao comportamento espectral do solo, como a composição mineralógica, em que a distribuição granulométrica e os demais atributos foram associados em parte a origem (local de coleta) das amostras.

Verificou-se também atribuição de amostras de locais de coleta com características semelhantes nos mesmos grupos (Tabela 3). Todas as amostras da fazenda A (com textura argilosa ou muito argilosa) foram alocadas em grupos que continham quase que exclusivamente amostras deste local; entretanto, estas amostras foram separadas em duas partes, nos agrupamentos com quatro e cinco grupos, e uma destas partes (grupos I e II, respectivamente) foi composta por amostras mais argilosas e com maior teor de ferro, o que indicou que, embora agrupadas, houve ainda variação nas amostras deste local. As amostras das fazendas $\mathrm{Ce}$ $\mathrm{E}$ foram atribuídas a um mesmo grupo, por apresentar albedo muito baixo e feições de absorção relativas a óxidos, hidróxidos e oxi-hidróxidos de ferro bastante acentuadas. Também as amostras das fazendas B e D foram reunidas e corresponderam, na maior parte, a solos de textura arenosa e média ou solos argilosos,

Tabela 3. Tabela de contingência do número de observações em cada local de coleta (fazenda), nos grupos obtidos pela análise de agrupamento por "fuzzy c-means".

\begin{tabular}{lcccccc}
\hline Grupo & \multicolumn{7}{c}{ Local de coleta (fazenda) } & \multirow{2}{*}{$\mathrm{R}^{2}(\mathrm{U})$} \\
\cline { 2 - 5 } & $\mathrm{A}$ & $\mathrm{B}$ & $\mathrm{C}$ & $\mathrm{D}$ & $\mathrm{E}$ & \\
\hline I & 2 & 17 & 2 & 12 & 0 & \\
II & 0 & 0 & 4 & 0 & 18 & 0,682 \\
III & 73 & 1 & 0 & 0 & 0 & \\
\hline I & 45 & 0 & 0 & 0 & 0 & \\
II & 0 & 0 & 4 & 0 & 18 & 0 \\
III & 0 & 18 & 2 & 12 & 0 & \\
IV & 30 & 0 & 0 & 0 & 0 & \\
I & 0 & 2 & 2 & 8 & 0 & \\
II & 44 & 0 & 0 & 0 & 0 & \\
III & 3 & 16 & 0 & 4 & 0 & 0,750 \\
IV & 0 & 0 & 4 & 0 & 18 & \\
V & 28 & 0 & 0 & 0 & 0 & \\
\hline
\end{tabular}

com distribuição granulométrica muito próxima da dos solos de textura média. Contudo, estas amostras foram separadas em dois grupos, no agrupamento que continha cinco grupos, e parte foi atribuída ao grupo I, com mais amostras da fazenda $\mathrm{D}$, e parte agrupada no grupo III, no qual predominaram amostras da fazenda B. Assim, houve variação nas amostras das fazendas B e D, embora tenham sido reunidas nos agrupamentos com três e quatro grupos, com maior semelhança entre si, do que em relação às demais amostras analisadas.

Os valores de $R^{2}(U)$, referentes à relação entre a divisão das amostras em grupos e em locais de coleta, foram elevados (Tabela 3). Portanto, ficou evidente que a divisão das amostras em grupos, por meio dos dados radiométricos, permitiu agrupar pontos de locais semelhantes quanto à textura e à mineralogia.

A discriminação das amostras por classe textural, através da RLM, foi realizada apenas com as CP1 e 3 como variáveis preditoras, pois o uso somente destas $\mathrm{CP}$ proporcionou as maiores acurácias e índice $\mathrm{k}$ para o grupo de validação (Tabela 4). Quanto às acurácias associadas aos modelos de RLM, observou-se que, embora a $A_{G}$ tenha sido boa, com 0,70 , pela análise das $A_{M}$ e $A_{U}$, os melhores desempenhos dos modelos ocorreram para as classes argilosa e muito argilosa, com $\mathrm{A}_{\mathrm{U}}$ de 0,65 e 0,83 , respectivamente, mais bem representadas pelo conjunto de dados (correspondentes a 43 e $36 \%$ das amostras, respectivamente) do que as amostras de textura arenosa e média (7 e 14\% das amostras estudadas, respectivamente). Assim, a menor representatividade das amostras de textura arenosa e média pode ter prejudicado a obtenção de modelos de discriminação acurados, além da avaliação dos modelos obtidos. $\mathrm{O}$ índice $\mathrm{k}$ de 0,51 indicou como moderada a classificação obtida, o que reflete a acurácia

Tabela 4. Matriz de confusão para validação da regressão logística multinomial, índice $k$ e acurácias do método $\left(A_{M}\right)$, para o usuário $\left(\mathrm{A}_{\mathrm{U}}\right)$ e global $\left(\mathrm{A}_{\mathrm{G}}\right)$.

\begin{tabular}{|c|c|c|c|c|c|c|}
\hline \multirow{2}{*}{$\begin{array}{l}\text { Textura } \\
\text { estimada }\end{array}$} & \multicolumn{4}{|c|}{ Textura observada } & \multirow{2}{*}{ Total } & \multirow[t]{2}{*}{$\mathrm{A}_{\mathrm{U}}$} \\
\hline & Arenosa & Média & Argilosa & Muito argilosa & & \\
\hline Arenosa & 0 & 0 & 0 & 0 & 0 & 0,00 \\
\hline Média & 3 & 2 & 0 & 0 & 5 & 0,40 \\
\hline Argilosa & 0 & 2 & 13 & 5 & 20 & 0,65 \\
\hline Muito argilosa & 0 & 0 & 3 & 15 & 18 & 0,83 \\
\hline Total & 3 & 4 & 16 & 20 & \multicolumn{2}{|c|}{$\mathrm{A}_{\mathrm{G}}=0,698$} \\
\hline $\mathrm{A}_{\mathrm{M}}$ & 0,00 & 0,50 & 0,81 & 0,75 & \multicolumn{2}{|c|}{$\mathrm{k}=0,514$} \\
\hline
\end{tabular}


de classificação satisfatória para as amostras argilosas e muito argilosas, mas, ao mesmo tempo, insatisfatória para as amostras de textura arenosa e média.

Os resultados obtidos corroboraram os apresentados por Mouazen et al. (2005), que obtiveram classificação correta elevada para amostras argilosas, porém baixa para amostras arenosas. Estes autores observaram que isto ocorreu em razão da baixa representatividade da classe arenosa, ou seja, pequena quantidade de amostras, e pela baixa correlação entre as informações espectrais e a fração areia dos dados estudados. Esta baixa correlação não foi observada no presente estudo, o que pode ter ocorrido, por exemplo, pela variação da composição mineralógica e orgânica dos solos avaliados.

Os valores de RPD acima de 2,0 qualificaram como ótimos os desempenhos de predição para argila, silte e areia, de acordo com critério de avaliação descrito por Chang et al. (2001) (Figura 5). Foram observados também elevados valores de $\mathrm{R}^{2}$ e baixos erros de predição, descritos pelo parâmetro RMSE.
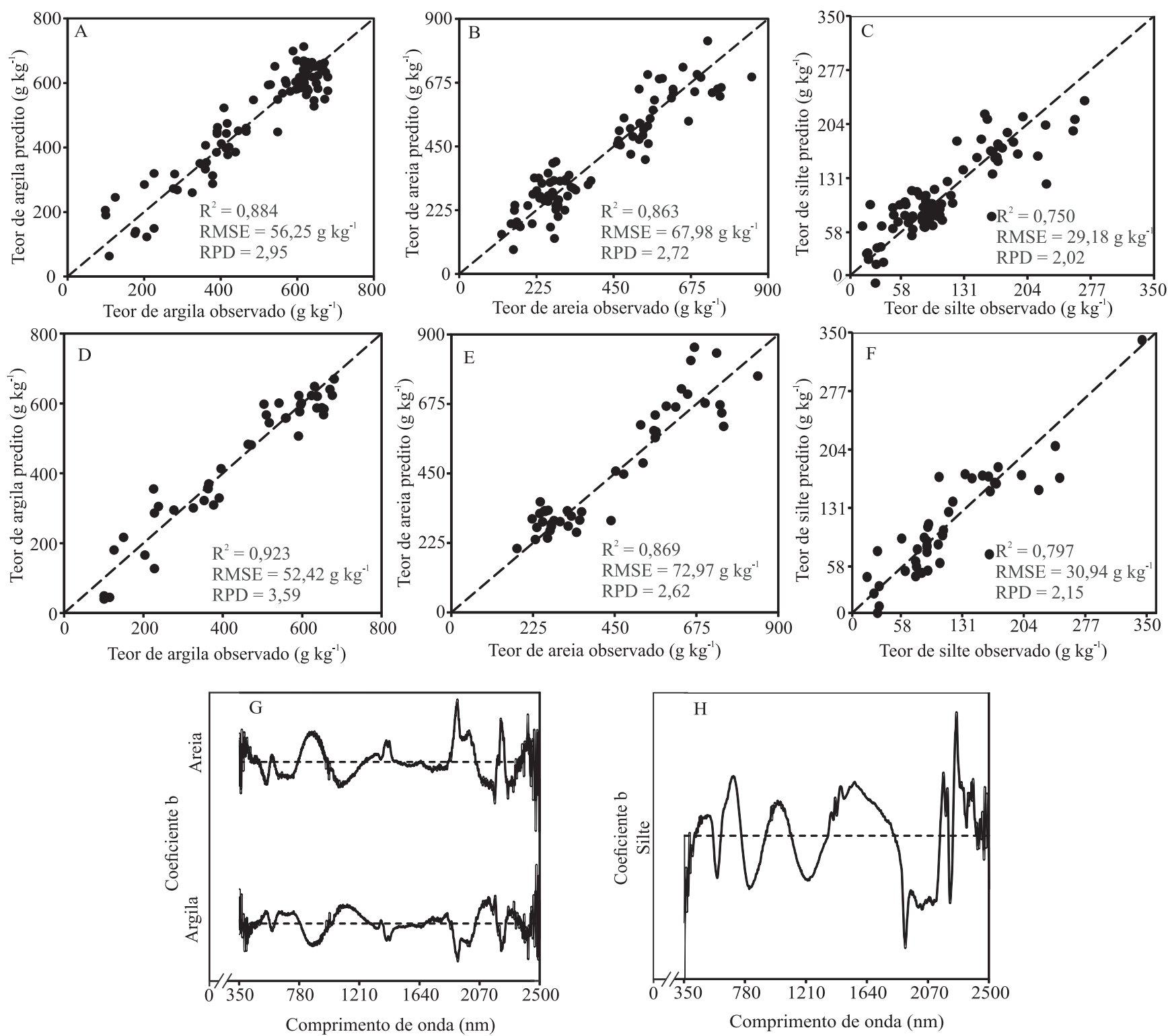

Figura 5. Valores observados e preditos (PLSR) na validação cruzada (A, B, C) e na validação com dados independentes (D, E, F) e coeficientes b dos modelos de quantificação de argila e areia $(\mathrm{G})$ e silte $(\mathrm{H})$. Pré-tratamentos (todos centrados pela média) aplicados aos dados radiométricos: argila, "standard normal variate" (SNV) e Savitzky-Golay (SG); areia, SNV e filtro mediano; silte, "multiple scattle correction" (MSC) e "wavelets". 
Assim, o desempenho dos modelos de predição foi comparável ou superior ao de boa parte dos desempenhos obtidos em outros trabalhos como, por exemplo, os descritos por Shepherd \& Walsh (2002) e Viscarra Rossel et al. (2009), que obtiveram $\mathrm{R}^{2}$ de 0,85 e de 0,78 , com RMSE de 75,0 $\mathrm{g} \mathrm{kg}^{-1}$, para estimativas do teor de argila em solos da África e Austrália, respectivamente. Como resultados de estudos feitos no Brasil, podem ser citados os obtidos por Demattê \& Garcia (1999), com $\mathrm{R}^{2}$ de 0,90 para a determinação dos teores de argila em área no Estado do Paraná. Nanni \& Demattê (2006) obtiveram R ${ }^{2}$ de 0,92 e 0,80 e Ferraresi et al. (2012) $\mathrm{R}^{2}$ de 0,85 e 0,87 , na quantificação das frações argila e areia, respectivamente, em áreas de estudo nos Estado de São Paulo e Goiás. Vendrame et al. (2012) em escala regional de amostragem do teor de argila em Latossolo do Cerrado encontraram valores de $\mathrm{R}^{2}$ de 0,83 e 0,74 , nas etapas de calibração e validação, respectivamente. Tais resultados, em conjunto com os obtidos no presente trabalho, indicam alta repetitividade do bom desempenho de técnicas espectroscópicas, em diferentes regiões do País, o que confirma seu potencial para auxiliar os métodos convencionais de descrição do solo.

Com os coeficientes b dos modelos de quantificação das frações argila, areia e silte (Figura 5), verificouse que a predição foi influenciada por comprimentos de onda no visível até cerca de $1.200 \mathrm{~nm}$, relativos especialmente aos teores de óxidos, hidróxidos e oxi-hidróxidos de ferro, assim como por feições de absorção próximas de 1.900 e $2.200 \mathrm{~nm}$, ocasionadas principalmente por filossilicatos e gibbsita (Stenberg et al., 2010). Além disto, os coeficientes b dos modelos de predição dos teores de argila e areia foram quase simétricos, em relação ao eixo $\mathrm{x}$, o que indica que as mesmas regiões do espectro têm importância nas estimativas destes atributos.

Considerando-se os bons resultados com os modelos de predição (análise quantitativa), principalmente para os teores de argila e areia, aliados aos resultados obtidos até o momento em outros estudos, o uso da espectroscopia de reflectância pode ser uma boa alternativa, especialmente para regiões semelhantes à estudada, reduzindo-se custos, tempo gasto e impacto ambiental decorrentes da determinação da textura do solo pelos métodos convencionais.

\section{Conclusões}

1. A avaliação do comportamento espectral médio das classes texturais mostra que é possível separar amostras de solo diferentes quanto à textura, por meio da análise morfológica (forma, feição e intensidade) e da comparação das curvas espectrais.

2. A análise de componentes principais, o agrupamento por "fuzzy c-means" e a regressão logística multinomial indicam o potencial semiquantitativo dos dados de reflectância pelo VIS-NIR-SWIR, tanto para a caracterização e discriminação textural quanto para a segregação de amostras de solo com características distintas, com relação a sua mineralogia.

3. A viabilidade da predição principalmente dos teores de argila e areia por técnicas espectroscópicas comprova o potencial destas para auxiliar na caracterização do solo e de sua variabilidade.

\section{Agradecimentos}

À Fundação de Amparo à Pesquisa do Estado de São Paulo (Fapesp), pelo financiamento do espectrorradiômetro FieldSpec 3; à equipe do projeto Agspec, da Embrapa Monitoramento por Satélite, pelos recursos logísticos de campo e coleta de dados; e à equipe do Laboratório de Solos e do GeoCis (Grupo de Pesquisas de Geotecnologia em Ciência do Solo), da Escola Superior de Agricultura Luiz de Queiroz (Esalq), pelo preparo e processamento das amostras.

\section{Referências}

BAUMGARDNER, M.F.; SILVA, L.F.; BIEHL, L.L.; STONER, R. Reflectance properties of soils. Advances in Agronomy, v.38, p.1-44, 1985. DOI: 10.1016/S0065-2113(08)60672-0.

BELLINASO, H.; DEMATTÊ, J.A.M.; ROMEIRO, S.A. Soil spectral library and its use in soil classification. Revista Brasileira de Ciência do Solo, v.34, p.861-870, 2010. DOI: 10.1590/ S0100-06832010000300027.

BEZDEK, C.J.; EHRLICH, R.; FULL, W. FCM: the fuzzy c-means clustering algorithm. Computers and Geosciences, v.10, p.191-203, 1984. DOI: 10.1016/0098-3004(84)90020-7.

BOUYOUCOS , G.J. Hydrometer method improved for making particle size analysis of soils. Agronomy Journal, v.54, p.464-465, 1962. DOI: 10.2134/agronj1962.00021962005400050028x.

CARVALHO JUNIOR, W. de; PEREIRA, N.R.; BHERING, S.B.; AMARAL, F.C.S. do; CHAGAS, C. da S.; GONÇALVES, A.O.; ÁGLIO, M.L.D.; AMORIM, A.M.; LOPES, C.H.L.; EARP, C.G. de S.; DANIEL FILHO, A.C.B.; RODRIGUES, R.S.; SILVA, N.C. e. Levantamento de reconhecimento de baixa intensidade dos 
solos do município de Maracaju-MS. Rio de Janeiro: Embrapa Solos, 2009. 1 mapa, color. Escala 1:100.000.

CHANG, C.W.; LAIRD, D.A.; MAUSBACH, M.J.; HURBURGH JUNIOR, C.R. Near-infrared reflectance spectroscopy - principal components regression analyses of soil properties. Soil Science Society of America Journal, v.65, p.480-490, 2001. DOI: 10.2136/ sssaj2001.652480x.

CONGALTON, R.G.; GREEN, K. Assessing the accuracy of remotely sensed data: principles and practices. $2^{\text {nd }}$ ed. Boca Raton: CRC Press, 2009. 183p.

DEMATTÊ, J.A.M. Characterization and discrimination of soils by their reflected electromagnetic energy. Pesquisa Agropecuária Brasileira, v.37, p.1445-1458, 2002. DOI: 10.1590/ S0100-204X2002001000013.

DEMATTÊ, J.L.I.; DEMATTÊ, J.A.M. Ambientes de produção como estratégia de manejo na cultura de cana-de-açúcar. Informações Agronômicas, n.127, p.10-18, 2009.

DEMATTÊ, J.A.M.; GARCIA, G.J. Alteration of soil properties through a weathering sequence as evaluated by spectral reflectance. Soil Science Society of America Journal, v.63, p.327-342, 1999. DOI: 10.2136/sssaj1999.03615995006300020010x.

DEMATTÊ, J.A.M.; SOUSA, A.A.; ALVES, M.C.; NANNI, M.R.; FIORIO, P.R.; CAMPOS, R.C. Determing soil water status and other soil characteristics by spectral proximal sensing. Geoderma, v.135, p.179-195, 2006. DOI: 10.1016/j.geoderma.2005.12.002.

EMBRAPA MONITORAMENTO POR SATÉLITE. AGSPEC. Disponível em: <http://www.cnpm.embrapa.br/projetos/agspec/ index.html>. Acesso em: 14 dez. 2013.

FERRARESI, T.M.; SILVA, W.T.L. da; MARTIN-NETO, L.; SILVEIRA, P.M. da; MADARI, B.E. Espectroscopia de infravermelho na determinação da textura do solo. Revista Brasileira de Ciência do Solo, v.36, p.1769-1777, 2012. DOI: 10.1590/S0100-06832012000600010.

GEOLOGIA e recursos minerais do Estado do Mato Grosso do Sul. Campo Grande: Serviço Geológico do Brasil - CRPM, 2006. 121p.

GIORDANI, P.; FERRARO, M.B. Package 'fclust': fuzzy clustering. Version 1.0. Vienna: R Foundation for Statistical Computing, 2013.

HENGL, T.; TOOMANIAN, N.; REUTER, H.I.; MALAKOUTI, M.J. Methods to interpolate soil categorical variables from profile observations: lessons from Iran. Geoderma, v.140, p.417-427, 2007. DOI: 10.1016/j.geoderma.2007.04.022.

LEVENE, H. Robust tests for equality of variances. In: OLKIN, I. (Ed.). Contributions to probability and statistics: essays in honor of Harold Hotelling. Palo Alto: Stanford University, 1960. p.278-292.

MADARI, B.E.; REEVES III, J.B.; MACHADO, P.L.O.A.; GUIMARÃES, C.M.; TORRES, E.; MCCARTY, G.W. Mid- and near-infrared spectroscopic determination of soil compositional parameters and structural indices in two Ferralsols. Geoderma, v.136, p.245-259, 2006. DOI: 10.1016/j.geoderma.2006.03.026.

MEYER, D.; ZEILEIS, A.; HORNIK, K. ved: Visualizing Categorical Data. R package version 1.3-1. Vienna: R Foundation for Statistical Computing, 2013.
MIRANDA, E.E. de (Coord.). Brasil em Relevo. Campinas: Embrapa Monitoramento por Satélite, 2005. Disponível em: <http:// www.relevobr.cnpm.embrapa.br>. Acesso em: 29 nov. 2013.

MOTTA, P.E.F. da; CARVALHO FILHO, A. de; PEREIRA, N.R.; BHERING, S.B.; CARVALHO JÚNIOR, W. de; ÁGLIO, M.L.D.; AMORIM, A.M.; TAKAGI, J.S.; LOPES, C.H.L.; RODRIGUES, R.S.; SILVA, N.C.L. e. Levantamento de reconhecimento de baixa intensidade dos solos do município de Campo Grande-MS. Rio de Janeiro: Embrapa Solos, 2010. 1 mapa, color. Escala 1:100.000.

MOUAZEN, A.M.; KAROUI, R.; DE BAERDEMAEKER, J.; RAMON, H. Classification of soil texture classes by using soil visual near infrared spectroscopy and factorial discriminant analysis techniques. Journal of Near Infrared Spectroscopy, v.13, p.231-240, 2005. DOI: 10.1255/jnirs.541.

NANNI, M.R.; DEMATTÊ, J.A.M. Spectral reflectance methodology in comparison to tradicional soil analysis. Soil Science Society of America Journal, v.70, p.393-407, 2006. DOI: 10.2136/sssaj2003.0285.

OLIVEIRA, V.A. de; PEREIRA, N.R.; CARVALHO JUNIOR, W. de; BHERING, S.B.; GONÇALVES, A.O.; ZARONI, M.J.; ÁGLIO, M.L.D.; SOARES, J.; LOPES, C.H.L.; RODRIGUES, R.S.; SILVA, N.C.L. e. Levantamento de reconhecimento de baixa intensidade dos solos do município de Jaraguari-MS. Rio de Janeiro: Embrapa Solos, 2009. 1 mapa, color. Escala 1:100.000.

PROJETO RADAMBRASIL. Folha SF.21 Campo Grande: geologia, geomorfologia, pedologia, vegetação, uso potencial da terra. Rio de Janeiro: Ministério das Minas e Energia, 1982. 412p. il. (Levantamento de recursos naturais, 28). Contém 5 mapas.

R DEVELOPMENT CORE TEAM. R: a language and environment for statistical computing. Vienna: R Foundation for Statistical Computing, 2012.

RAIJ, B. van; ANDRADE, J.C. de; CANTARELLA, H.; QUAGGIO, J.A. Análise química para avaliação de solos tropicais. Campinas: IAC, 2001. 285p.

RICHARDS, J.A. Remote sensing digital image analysis: an introduction. $5^{\text {th }}$ ed. Heidelberg: Springer, 2013. 494p. DOI: 10.1007/978-3-642-30062-2.

SANTOS, H.G. dos; JACOMINE, P.K.T.; ANJOS, L.H.C. dos; OLIVEIRA, V.A. de; LUMBRERAS, J.F.; COELHO, M.R.; ALMEIDA, J.A. de; CUNHA, T.J.F.; OLIVEIRA, J.B. de. Sistema brasileiro de classificação de solos. 3.ed. rev. e ampl. Brasília: Embrapa, 2013. 353p.

SHEPHERD, K.D.; WALSH, M.G. Development of reflectance spectral libraries for characterization of soil properties. Soil Science Society of America Journal, v.66, p.988-998, 2002. DOI: 10.2136/SSSAJ2002.0988.

SILVA, E.F. da; COELHO, M.R.; AMARAL, F.C.S. do; BHERING, S.B.; CARVALHO JUNIOR, W. de; PEREIRA, N.R.; AGLIO, M.L.D.; LOPES, C.H.L.; TAKAGI, J.S.; EARP, C.G. de SÁ; RODRIGUES, R.S.; SILVA, N.C. e. Levantamento de reconhecimento de baixa intensidade dos solos do município de Aquidauana-MS. Rio De Janeiro: Embrapa Solos, 2009. 1 mapa, color. Escala 1:100.000.

Pesq. agropec. bras., Brasília, v.48, n.12, p.1569-1582, dez. 2013 DOI: 10.1590/S0100-204X2013001200006 
SOUSA JUNIOR, J.G.; DEMATTÊ, J.A.M.; ARAÚJO, S.R. Modelos espectrais terrestres e orbitais na determinação de teores de atributos dos solos: potencial e custos. Bragantia, v.70, p.610-621, 2011. DOI: 10.1590/S0006-87052011000300017.

STENBERG, B.; VISCARRA ROSSEL, R.A.; MOUAZEN, A.M.; WETTERLINDD, J. Visible and near infrared spectroscopy in soil science. Advances in Agronomy, v.107, p.163-215, 2010. DOI: 10.1016/S0065-2113(10)07005-7.

VARMUZA, K.; FILZMOSER, P. Introduction to multivariate statistical analysis in chemometrics. Boca Raton: CRC Press, 2009. 336p. DOI: 10.1201/9781420059496.

VASQUES, G.M.; GRUNWALD, S.; SICKMAN, J.O. Comparison of multivariate methods for inferential modeling of soil carbon using visible/near-infrared spectra. Geoderma, v.146, p.14-25, 2008. DOI: 10.1016/j.geoderma.2008.04.007.

VENABLES, W.N.; RIPLEY, B.D. Modern applied statistics with S. $4^{\text {th }}$ ed. New York: Springer, 2002. DOI: 10.1007/978-0387-21706-2.

VENDRAME, P.R.S.; MARCHÃO, R.L.; BRUNET, D.; BECQUER, T. The potential of NIR spectroscopy to predict soil texture and mineralogy in Cerrado Latosols. European Journal of Soil Science, v.63, p.743-753, 2012. DOI: 10.1111/j.13652389.2012.01483.x.

VICENTE, L.E.; SOUZA FILHO, C.R. de. Identification of mineral components in tropical soils using reflectance spectroscopy and advanced spaceborne thermal emission and reflection radiometer (ASTER) data. Remote Sensing of Environment, v.115, p.1824-1836, 2011. DOI: 10.1016/j.rse.2011.02.023

VISCARRA ROSSEL, R.A. ParLeS: Software for chemometric analysis of spectroscopic data. Chemometrics and Intelligent Laboratory Systems, v.90, p.72-83, 2008. DOI: 10.1016/j. chemolab.2007.06.006.

VISCARRA ROSSEL, R.A.; CATTLE, S.R.; ORTEGA, A.; FOUAD, Y. In situ measurements of soil colour, mineral composition and clay content by Vis-NIR spectroscopy. Geoderma, v.150, p.253-266, 2009. DOI: 10.1016/j. geoderma.2009.01.025.

WHITE, R.E. Principles and practice of soil science: the soil as a natural resource. $4^{\text {th }}$ ed. Oxford: Blackwell, 2005. 384p.

XIE, X.L.; BENI, G. A validity measure for fuzzy clustering. IEEE Transactions on Pattern Analysis and Machine Intelligence, v.13, p.841-847,1991. DOI: 10.1109/34.85677.

Recebido em 23 de outubro de 2013 e aprovado em 29 de novembro de 2013 